\title{
IAMSE 2021—Plenary Session: Top 10 Ways an Instructional Designer Can Help You Define the New Normal
}

\author{
Atsusi Hirumi ${ }^{1}$ (i) \\ Accepted: 3 September 2021 / Published online: 17 September 2021 \\ (c) International Association of Medical Science Educators 2021
}

\begin{abstract}
Along with the continued exponential growth of information and treatment options, healthcare practitioners must now deal with increasing documentation requirements, varying data systems, altering health plans, rising patient expectations, loss of autonomy, and demands to decrease costs while increasing revenue. Add to the complexity, the need to transform coursework and clinical experiences to address the constraints presented by COVID-19 can quickly overwhelm medical educators. Given such prodigious challenges, educational specialists with a solid understanding of learning research and theory, instructional design, and emerging technology can play a vital role in designing engaging learning experiences. In this plenary session, Dr. Atsusi "2c" Hirumi illuminated 10 ways an instructional designer may help health science educators unlock the potential of the new normal based on his experience working with professionals in medical, healthcare, aviation, sports, and hospitality industries as well as faculty, staff, and administrators in K12 and higher education across five continents.
\end{abstract}

Keywords Instructional design · Evidence-based medical education $\cdot$ Plenary session $\cdot$ Keynote

After 30 plus years as a practicing instructional designer, I was both honored and thrilled with the opportunity to share what I believe are the 10 top ways an instructional designer may help health science educators define the new normal. Before I began my list, I thought it important to set the context by defining: What is Instructional Design (ID), and what is the New Normal? For many, ID is not a well-known field. In fact, my parents still ask me, "What do you actually do for a living?" Over time, I have found it useful to delimit the field by asking something familiar, "Have you ever taken a bad university course or attended poorly designed training?" Many have. One of the distinctive characteristics of training and university courses is that they are typically created by subject matter experts (SMEs). About 50 years ago, the military figured out that SMEs are essential; you must have subject matter expertise to design effective coursework. However, SMEs may not have the background, knowledge, or professional preparation in teaching, learning, and designing to create high-quality training and educational materials. Instructional designers are experts in how and why people

Atsusi Hirumi

Atsusi.Hirumi@ucf.edu

1 Department of Learning Sciences, University of Central Florida, Orlando, FL, USA learn, how to design training and educational systems, and how to work with SMEs to mold content into effective, efficient, and engaging coursework.

How about the new normal? What will it be like when we return to campus and get back to "normal" operations? I do not believe anyone truly knows what the new normal will be like 5, 4, even 3 years from now. However, there are a few things I think we can assume. For example, I think we can assume that the amount of medical knowledge available to humankind will continue to accumulate exponentially [1], and that technology will also continue to advance at an accelerating rate $[2,3]$. The current pandemic also highlights, and as our first plenary speaker, Dr. David Gordon so well framed, the importance of thinking globally and acting locally. I also gave a shout out to Dr. Camille Bentley, our second plenary speaker, for her global efforts to advance healthcare, particularly in low-income, resource-scarce countries. With such worldwide efforts, we must also keep in mind that connectivity will remain an issue abroad as well as in the USA. We also know that traditional, teacher-directed instructional methods, such as lecturing, do not engage twenty-first century learners. We cannot assume that the methods used to educate healthcare professionals 5,10 , and 20 years ago will capture and sustain learners' attention in the new normal. Given these challenges and uncertainties... 


\section{What Can Instructional Designers Do To Help Health Science Educators Define The New Normal?}

\section{\#10 - Learning Styles}

I began my top 10 list by asking, "Do you believe in learning styles, and if so, do you do anything in particular to address learning styles?" After observing that not all, but a significant number said yes to both questions, I noted that research indicates that people may develop learning preferences (e.g., I do not like to read so I learn better with pictures), but are not born with learning styles. To support my claim, I contrasted the expected versus the typical results obtained from Aptitude Treatment Interaction (ATI) research. I then corrected item \#10 to read, "Myths and Misconceptions." I then suggested that instructional designers may help health science educators dispel other common educational myths and misconceptions, such as but not limited to the following: digital natives are better at multi-tasking; people are rightbrained or left-brained; adults have less capacity to learn at an older age; andragogy differs from pedagogy; 10,000 hrs. of practice will make you an expert; and people remember $10 \%$ of what they read, $20 \%$ of what they hear, $30 \%$ of what they see, and $50 \%$ of what they hear and see.

To remain within the hour allocated for my session, I provided brief overviews, particularly of the next three topics. Admittedly, the overviews do not do each topic justice, but serve to emphasize the basic premise of my talk.

\section{\#9 - Adaptive Competency-Based Educational Systems}

Today's educational system has reached its upper limit in terms of productivity $[4,5]$. Unlike other major sectors of society that have made significant advances over time, education remains marred in an industrial age model that holds time constant (e.g., with everyone beginning and ending courses at the same time). Yet, we know that individuals' educational needs and interests vary; thus, by holding time constant, we allow achievement to vary. To garner significant increases in educational productivity, we must allow time to vary and ensure everyone achieves mastery (or better). Table 1 compares key variables that distinguish competency-based education [6-8] versus industrial age models of education.

With expertise in teaching, learning, and design, instructional designers are particularly well positioned to help educators create individualized, time variable modules that include assessments and instructional strategies that facilitate studentcentered learning, and the mastery of key competencies, such as those delineated by the Entrustable Professional Activities.
Table 1 Comparison of key variables with an industrial versus a competency-based model of education

\begin{tabular}{lll}
\hline Variables & Industrial age model & Competency-based model \\
\hline Time & Constant (faculty-based) & Variable (self-paced) \\
Achievement & Varies (bell curve) & Constant (mastery) \\
Structure & Cohort (courses) & Individuals (modules) \\
Assessments & Certify and rank & Facilitate learning \\
Outcomes & $\begin{array}{c}\text { Discrete skills and knowl- } \\
\text { edge }\end{array}$ & Competences (e.g., EPAs) \\
Instruction & Teacher-directed & Student-centered \\
\hline
\end{tabular}

\section{\#8 - Performance Ecosystems}

Organizations typically employ different software applications to support core business functions, such as finance, talent management, research and development, communications, and marketing. Performance ecosystems integrate such applications to connect people and share data to enhance individual and organizational performance [9]. Instructional designers with their dedication to teaching and learning are well prepared to help create and improve key components of performance ecosystems, including (a) training to facilitate talent development, (b) job aids and micro learning to provide performance support, and (c) research to contribute to knowledge management.

\section{\#7 - Emerging Technologies}

Advances in virtual and mixed reality, artificial intelligence and machine learning, simulations, telehealth and telemedicine, and distributed learning systems, among others, hold promise for enhancing health science education. For the plenary session, I presented a graphic illustrating the plethora of Web 2.0 technologies that health science educators may now use to create, aggregate, curate, edit, organize, store, share, and integrate interactive multimedia content. I also argued that the abilities to create participatory learning spaces, memorable infographics, gamified content, and personal learning plans have become fundamental digital skills for twenty-first century educators. But who has the time to remain abreast of such emerging technologies? I suggested that IDs may play a vital role in helping health educators research, monitor, and track developments; compare, contrast, and evaluate; and demonstrate the use of and help integrate technology. Designers may also plan and conduct formative and summative evaluations to inform continuous improvement. In addition, IDs may help health science educators document their efforts and publish and present the results of integrating emerging technology to contribute to the knowledge-base and forward their academic careers. 


\section{\#6 - MedED-COTS}

MedED-COTS are defined as Commercial-Off-The-Shelf learning resources used to facilitate Medical Education. Table 2 presents a cursory list of MedED-COTS that students use to prepare for national board exams. The pervasive use of MedED-COTS has raised a number of concerns among faculty and students that I detailed during my presentation. Although I do not have space to summarize the concerns here, I do believe it is important to consider how MedED-COTS may facilitate learning.

It is evident why the vast majority of medical students utilize MedED-COTS; they contain a number of key features that health science faculty may neither have the time nor the resources to offer, including (a) robust question banks and flashcards that utilize spaced repetition to promote recall; (b) high-yield, high-quality multimedia content that may be viewed by topic, systems, or disorder; (c) extensive cross references to both internal resources and external contents, books, and journal articles; (d) visual and verbal mnemonics; (e) performance tracking; and (f) coaching and study planning.

With such powerful features, often combined in one platform, I believe the integration of MedED-COTS may optimize the use of available resources for several substantive reasons. Faculty may reduce the time they spend creating lectures, self-learning modules, and conventional assessment items, and thus spend more time facilitating active learning, and the development of higher order thinking skills by helping students interpret, apply, and evaluate core scientific facts, concepts, and principles. As the pandemic illustrated, MedED-COTS may also fill in gaps in the curriculum, particularly when human or material resources may be scarce. For students, the integration of MedED-COTS may give them more opportunities to prepare for national board exams using resources they already use on their own. MedED-COTS may also help students relate class work (career preparation) and out-of-class work (test preparation), and correlate core scientific concepts to clinical practice, thus increasing trust, satisfaction, and engagement with the curriculum.

Similar to the ways an instructional designer may help educators integrate the use of (other) emerging

Table 2 Cursory list of MedED-COTS

\begin{tabular}{lll}
\hline AMBOSS & Kaplan & Pathoma \\
\hline ANKI & Lange & Physeo \\
Acquifer & Lecturio & Picmonic \\
Boards and Beyond & Lippincott & Sktchy Medical \\
Doctors in Training & Online MedED & USMLE/Scholar-Rx \\
Draw It to Know It & Osmosis & UWorld \\
\hline
\end{tabular}

technologies, I believe designers may help educators (a) research, monitor, and track the development of MedEDCOTS; (b) evaluate, compare, demonstrate, and integrate the use of such learning platforms; (c) conduct formative and summative evaluations; and (d) document efforts and findings to publish and present their efforts.

Before moving on with my list, I posited the basic premise of my presentation; that emerging educational trends and technology may increase productivity and access to educational resources as well as provide additional affordances, but they do not guarantee the quality of the educational experience. Learning management systems (LMS) is a prime example; LMS enabled thousands of educators to continue delivering coursework during the pandemic, but much of the resulting materials and methods were rightly labeled emergency remote teaching [10]. Of course, educators and those who supported their efforts are not to blame. Many put in a tremendous amount of time to meet students' needs, and their efforts must be commended.

At this point, I also noted a number of key trends, including but not limited to interprofessional education; telehealth and telemedicine; health disparities, diversity, and professional wellness; longitudinally integrated clinical experiences; symptoms-based curriculum; health systems science, big data analytics, and artificial intelligence. Then, similar to the use of technology, I suggested that we may not realize the potential afforded by these trends to advance health science education unless we clearly communicate and satisfy expectations.

\section{\#5 - Communicating and Satisfying Expectations (aka. Horizontal Alignment)}

One of the fundamental principles of ID is that it is systematic; the outputs of one design task as inputs to subsequent tasks to ensure the alignment of essential instructional elements. Figure 1 depicts the alignment of essential elements; namely, learning objectives, instructional strategy (including the chunking and sequencing of content information), and learner assessments. The problem is, these elements are frequently misaligned. Students are often (a) presented with a litany of objectives and/or fuzzy objectives that are neither clearly related to each other or to the content; (b) inundated with resources that, without clear objectives, are difficult to discern in terms of need to know versus nice to know information; and (c) asked to complete multiple-choice tests that assess students' acquisition of, rather than their ability to apply knowledge, when faculty expect students to develop critical, higher-order thinking skills.

To realize the potential of emerging trends and technology, I argue that we must clearly articulate our expectations in terms of what we want students to learn and do, and align instructional strategies and learner assessments to satisfy 


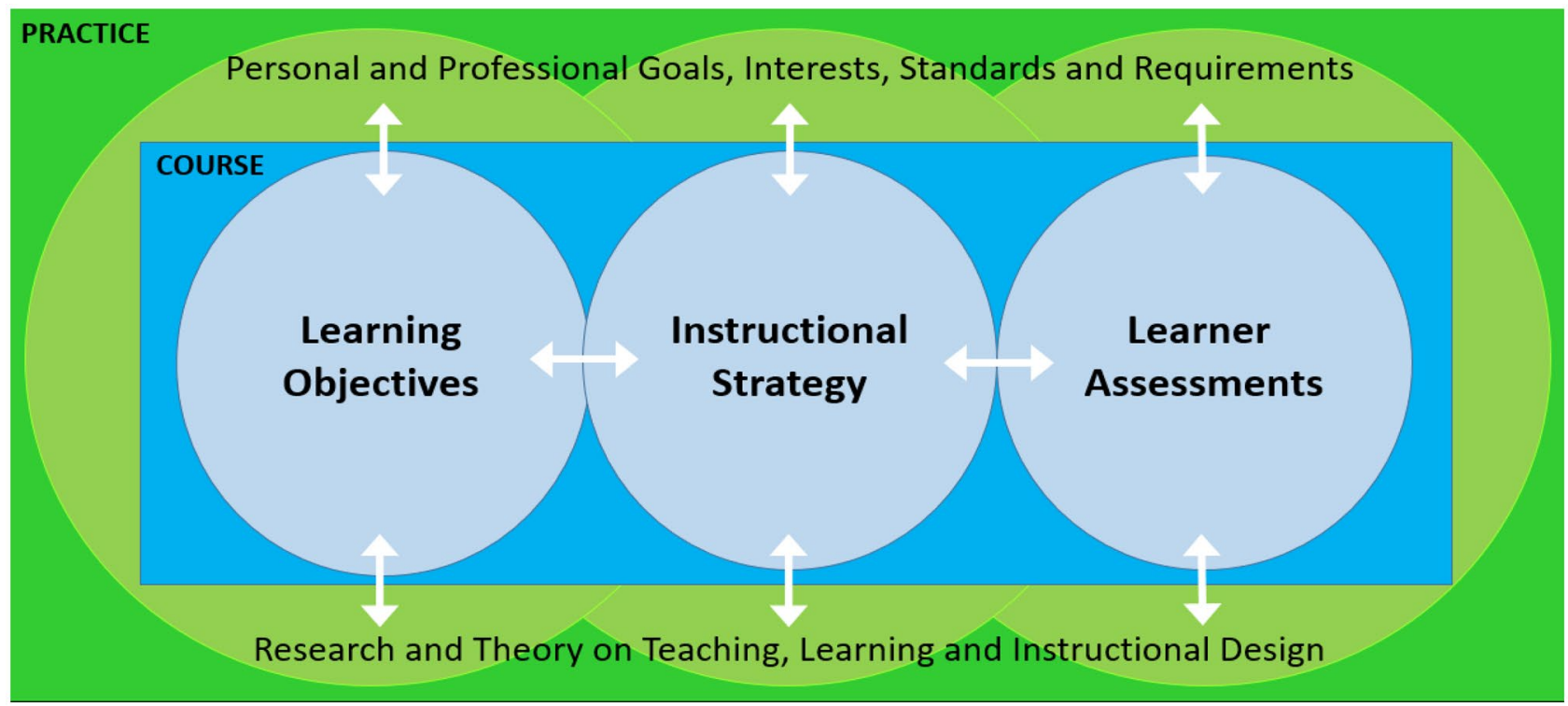

Fig. 1 Diagram illustrating the horizontal and vertical alignment of essential instructional elements

those expectations. Although conceptually, the alignment of these three basic elements is straightforward, in practice, such alignment is apparently much more challenging. Figure 2 illustrates the systematic design process I posited to ensure both the horizontal and the vertical alignment of the elements. The process is based on a widespread ADDIE model for instructional design that my primary co-author and colleague (Dr. Feroza Daroowalla) and I are adapting to facilitate evidence-based medical education (EBME) [11].

You can see from the diagram that we correlated basic design tasks to evidence-based medicine (EBM) using familiar terms such as articulating needs; asking questions about the Learner, Intervention, Context, and desired Outcomes (similar to PICO questions); and acquiring and appraising evidence, to facilitate the adoption of the model by health science educators. You can also see from the diagram that key (LICO) questions are asked to derive objectives, objectives are specified to determine learner assessments, and the objectives and assessments drive the formulation of an instructional strategy. The subsequent alignment of the instructional elements is characteristic of high-quality training and education and helps ensure that health science educators clearly communicate and meet expectations.

\section{\#4 - Grounded Design (aka. Vertical Alignment, Evidence-based Practice)}

Grounded design is defined as, "The systematic implementation of processes and procedures that are rooted in

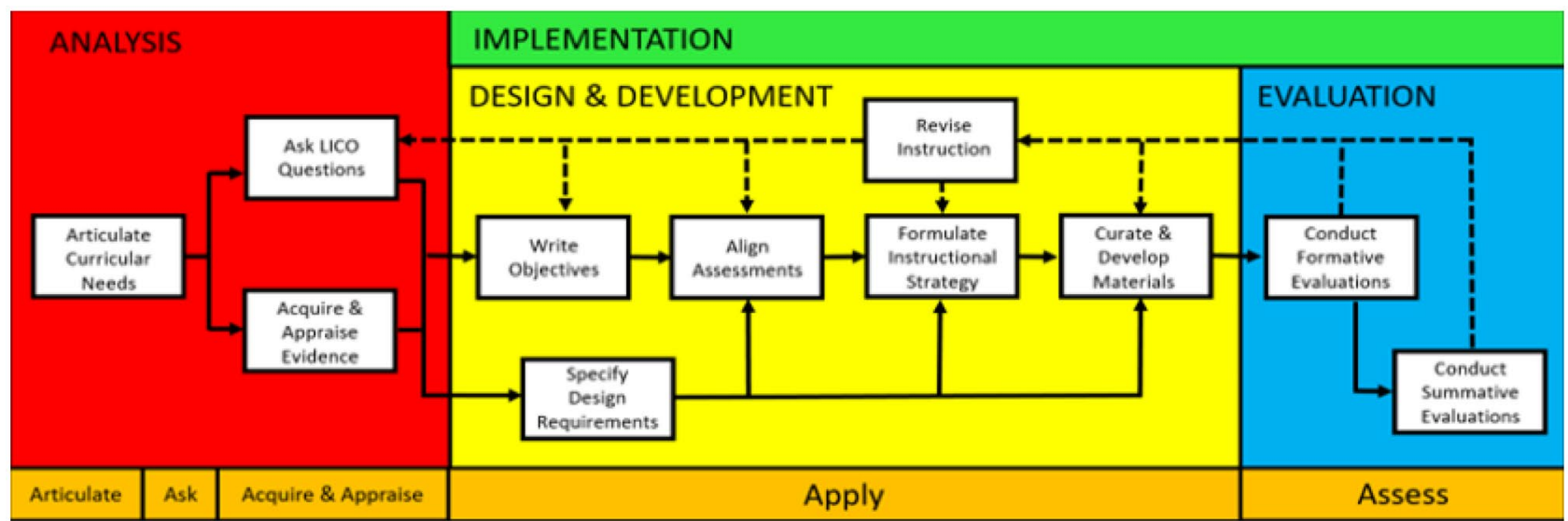

Fig. 2 Systematic instructional design process correlating EBME with EBM to facilitate adoption and the alignment of essential instructional elements 
established theory and research in human learning [12]." Three conditions for grounded design are consistent with evidence-based education; the design of instruction is (a) rooted in a defensible theoretical framework, (b) consistent with research findings, and (c) based on the desired outcomes and specified instructional approach. In other words, key design decisions (such as what to put online and what to facilitate in person for blended learning) may be traced back to research and theory as well as key contextual factors. To advance evidence-based practice, grounded design also emphasizes the importance of validating the design with successive implementations.

As depicted in Fig. 2, our adaptations to the pervasive ADDIE model also advance the systematic design process by making the practice of acquiring, appraising, and applying evidence (aka grounded design) explicit. Although space limitations prevent me from elaborating on the agile nature of the systematic design process, during the keynote, I highlighted how the model adapts to the context. Specifically, it facilitates three levels of involvement based on the needs and interests of health science educators during the acquisition and appraisal of evidence as illustrated using the old fishing analogy — give people fish or teach people how to fish:

- Level 3 - Time and interest (Let's go fishing)

- Level 2 - Some time and interest (Please tell me what's on the menu)

- Level 1 - Little time but some interest (Please serve me good fish)

- Level 0 - No time or interest (No fish please)

If health science educators have significant time and interest, instructional designers may work with them to acquire and appraise evidence. Together, they may search three domains to find relevant evidence, including research and theory on (a) how to achieve specified learning outcomes [13, 14], (b) how and why people learn $[15,16]$, and (c) how to plan the instructional approach $[17,18]$. They may then use published criteria [19] to appraise the evidence and formulate design specifications to apply the evidence. However, if medical educators want to base their instructional methods on evidence but have limited time, they may ask designers to acquire and appraise the evidence, brief them on their findings, and formulate relevant design specifications.

At this point in the presentation, I also provided one of my most requested handouts on ID Principles that illustrate what "evidence" and related design requirements may look like from several theoretical perspectives. The design principles summarized in the handout may be viewed as an extensive menu of evidence-based design options. The designer, in turn, is responsible for explaining the derivation and application of the evidence, and the fishing analogy goes on...

\section{\#3 - Blended Learning}

Based on the assumption that blended learning will play a significant role in the new normal, I started discussing the topic by presenting two common graphics: one that differentiated face-to-face (f2f) versus online components of blended learning [20] (which I modified to further distinguish synchronous $\mathrm{f} 2 \mathrm{f}$ and online), and the second that illustrated how educators facilitate a flipped approach to blended learning [21].

To portray how instructional designers may further advance blended learning, I summarized a study completed for US Army Intelligence. In short, the Department of Defense was looking for blended solutions to optimize $\mathrm{f} 2 \mathrm{f}$ class time in military school houses and was asked to develop a method for determining which aspects of the training to put on line and which aspects to facilitate in class. An extensive analysis of their conventional training resulted in a three-stage process that examined the nature of (a) the learning objectives, (b) the training context, and (c) the prescribed instructional strategy. The resulting flowcharts illustrated how the application of an instructional strategy, along with the stability of related media, may be used to further inform the blended design of synchronous and asynchronous interactions [22].

I then provided another popular handout that outlines a range of grounded instructional strategies that may be used to design and sequence vital online interactions. When I began to study online learning, it became apparent that good instructors clarify expectations, provide meaningful feedback, tell stories, and facilitate many other interactions in conventional classroom settings to engage students, but they do so intuitively, based on verbal and non-verbal cues. I also found that these interactions often disappear when faculty first moved online. Online interactions had to be carefully planned and sequenced as an integral part of online learning to facilitate the achievement of desired outcomes [23, 24]. The instructional strategies also provided a strong pedagogical foundation for determining what aspects of a blended lesson to facilitate synchronously and asynchronously. Thus, to complete the discussion of blended learning, I depicted how the 5E instructional strategy may be used to design a blended lesson on pulmonary physiology and provided another handout that detailed the $5 \mathrm{E}$ example.

\section{\#2 - Engaging 21st Century Learners}

Another assumption I believe we can make about the future of health science education is that we must continue to seek alternative ways to engage learners. To support such claims, 
Fig. 3 InterPLAY experience arc distinguishing key waypoints for creating engaged stories

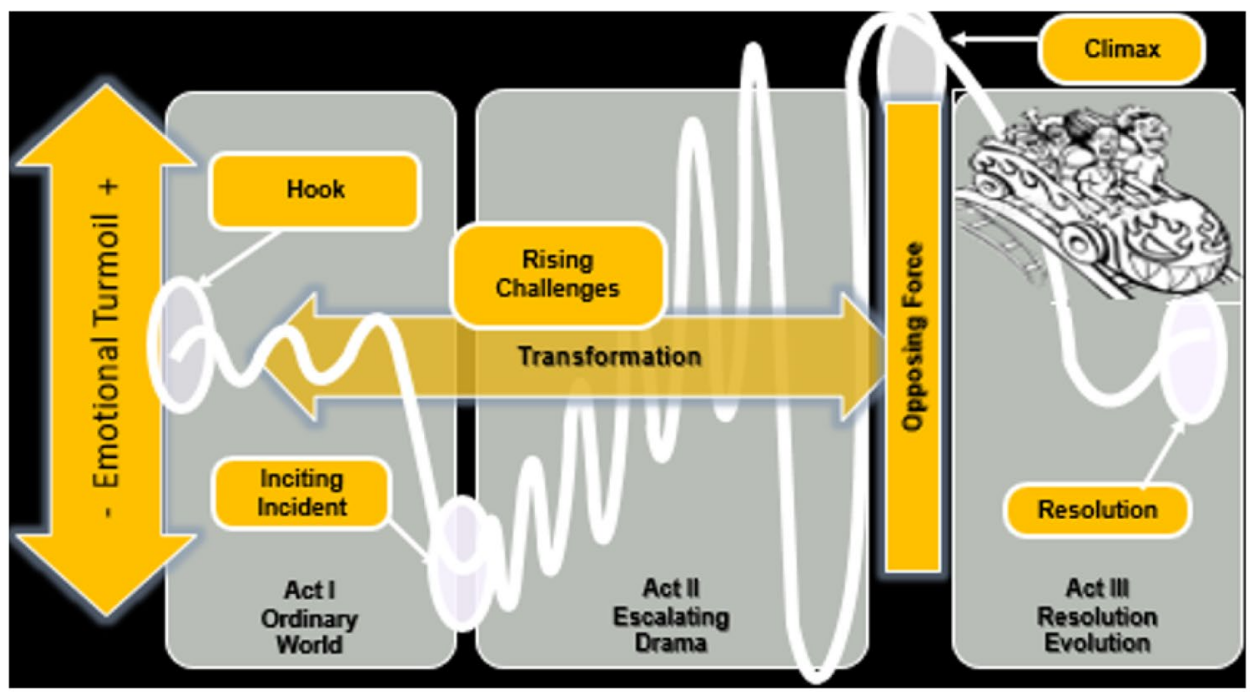

I portrayed the diversity that may now be found among a subpopulation of twenty-first century learners and argued that we can no longer assume that traditional teacher-directed instructional methods will motivate them. I then presented a brief overview of the ARCS model of motivational design [25, 26] and suggested its use because it offers a parsimonious method for analyzing students' motivation to learn and provides actionable data on students' perceived levels of Attention, Relevance, Confidence, and Satisfaction that may then be used to prescribe concrete tactics for engaging learners.

In addition to the ARCS model, I depicted the Inter$P L A Y$ instructional strategy that applies key conventions of interactive entertainment (i.e., story, play, and game) to create engaging learning experiences [27-30]. Specifically, I showed how InterPLAY may be applied to facilitate casebased learning, noting how MedED-COTS (\#5 on the top ten list) may be integrated to either push information to learners or enable learners to pull information when needed to diagnose a case. I also presented Fig. 3 to illustrate how a story may be told to engage learners across cases.

\section{\#1 - Facilitating Change}

When instructional designers work with organizations and SMEs to design innovative educational programs, they often have to change people's dispositions about teaching and learning. As such, instructional designers frequently study change theory and are typically trained on change management tools and techniques. I have also learned that knowledge of how to foster creativity and innovation are vital for individuals and organizations to remain competitive in the twenty-first century. Thus, to complete my top 10 list, I presented key concepts associated with creativity and innovation to empower session participants to facilitate change. Specifically, I presented Table 3 that compared physical and psychological factors that are known to affect creativity and encouraged participants to reflect on whether their work and class conditions catalyzed or inhibited creativity.

I then discussed three additional ways that an instructional designer may help facilitate change, by (a) viewing human performance as a function of skills and knowledge, motivation and opportunity [31]; (b) addressing key characteristics that affect the adoption of innovations [32, 33]; and (c) analyzing and aligning the functional components of an educational system $[34,35]$. Finally, I concluded my top 10 list on an inspirational note by quoting the Dali Lama, "When you talk, you are only repeating what you already know. But if you listen, you may learn something new."

As health science educators seek to define the new normal, they must attend to a myriad of competing professional responsibilities, along with a plethora of emerging educational trends and technologies. For my plenary session, I hoped to delineate how instructional designers may be able to help health science educators optimize their time and resources, and unlock the potential of emerging trends and technologies to enhance student learning.

Table 3 Factors that inhibit or catalyze creativity

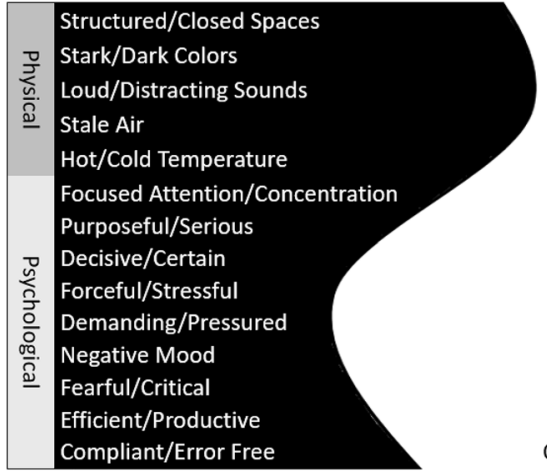

Flexible/Open Spaces Warm/Vibrant Colors Soft/Soothing Sounds Fresh Air Warm/Cool Temperature Unfocused Attention Playful/Reflective Contemplative/Flexible Eager/Calm Unpressured/Relaxed Positive Mood Confidence/Supportive Exploratory/Experimental Open/Constructive Failure 


\section{Declarations}

Ethics Approval Not applicable.

Consent to Participate Not applicable.

Consent for Publication Not applicable.

Competing Interests In accordance with Springer policy and my ethical obligation as a researcher, I am reporting that I have a non-paid, professional relationship with representatives from Lecturio ${ }^{\mathrm{TM}}$ and ScholarRx ${ }^{\mathrm{TM}}$, two companies that may be affected by the information reported in the enclosed paper.

\section{References}

1. Densen P. Challenges and opportunities facing medical education. Trans Am Clin Climatol Assoc. 2011;122:48-58.

2. Martins J. Accelerating Growth in Technology. Whizolosophy. Accessed September 27, 2019. https://whizolosophy.com/category/todays-world-projecting-tomorrow/gallery-charts-graphs/acceleratinggrowth-in-technology.

3. Tatu R. Race against the machine. ASEE. PRism. 2012;22(4):42.

4. Branson RK, \& Hirumi A. (1994). Designing the future: the Florida Schoolyear 2000 Initiative. In G. Kearsley \& W. Lynch (eds.). Educational Technology: Leadership Branson RK. Why the Schools Can't Improve: The Upper Limit Hypothesis. J Instr Dev. 1987;10(4):15-26.

5. Banathy BH. Systems design of education: a journey to create the future. Educational Technology Publications; 1991. Accessed June 19, 2021.

6. Colson R, Hirumi A. A framework for the design of online competency-based education (CBE) to promote student engagement. In: Rasmussen K, Northrup P, Colson R, editors. Handbook of Research on Competency-Based Education in University Settings. Hershey, PA: IGI Global; 2016. p. 168-85.

7. Reigeluth CM, Karnopp JR. Vision and action: reinventing schools through personalized competency-based education. Bloomington, IN: Marzano Resource; 2020.

8. İlhan E. Evaluation of competency based medical education curriculum. Int J Progress Educ. 2021;17(3):153-68. https://doi.org/ 10.29329/ijpe.2021.346.10.

9. Rosenberg M. Marc my words: in Learning and performance ecosystems...(Part 2). Learning Solutions Magazine. Accessed June 01, 2021. https://learningsolutionsmag.com/articles/1568/ marc-my-words-in-learning-and-performance-ecosystems-part- 2 .

10. Barbour MK, LaBonte R, Hodges $\mathrm{C}$, et al. Understanding pandemic pedagogy: differences between emergency remote, remote, and online teaching. January 2020. Accessed June 8, 2021. https:// search.ebscohost.com/login.aspx?direct $=$ true $\& \mathrm{db}=$ edsbas $\& A N=$ edsbas.. F79933D\&site $=$ eds-live $\&$ scope $=$ site.

11. Hirumi A, Daroowalla F. Building bridges across the cultural divide between instructional designers and multi-disciplinary medical educators. Concurrent session presented at: Association for Educational Communication and Technology virtual convention; November 2-7. 2020.

12. Hannafin MJ, Hannafin KM, Land SM, Oliver K. Grounded practice and the design of constructivist learning environments. Educ Technol Res Dev. 1997;45(3):101-117. Accessed June 14, 2021.

13. Aspegren K. BEME Guide No. 2: Teaching and learning communication skills in medicine - a review with quality grading of articles. Med Teach. 1999;21(6):563-570.

14. O'Dunn-Orto A, Hartling L, Campbell S, Oswald AE. Teaching musculoskeletal clinical skills to medical trainees and physicians: a best evidence in medical education systematic review of strategies and their effectiveness: BEME Guide No. 18. Med Teach. 2012;34(2):93-102.

15. Bransford J, Brown AL, Cocking RR. editors. How people learn: brain, mind, experience, and school. Washington, D.C.: National Academy Press; 1999.

16. Brown PC, Roediger HL III, McDaniel MA. Make it stick: the science of successful learning. Cambridge, Massachusetts: Harvard University Press; 2014.

17. Bernard RM, Abrami PC, Borokhovski E, Wade CA, Tamim RM, Surkes MA, and Bethel EC. A meta-analysis of three types of interaction treatments in distance education. Rev Educ Res. 2009;79(3):1,243-89.

18. Cook DA, Erwin PJ, Triola MM. Computerized virtual patients in health professions education: a systematic review and metaanalysis. Acad Med. 2010;85:1602-15890.

19. Harden R, Grant J, Buckley G, Hart I. Best evidence medical education-BEME Guide No 1. Med Teach. 1999;21(6):553-62.

20. Albiladi WS, Alshareef KK. Blended learning in English teaching and learning: a review of the current literature. Journal of Language Teaching and Research. 2019;10(2):232-8.

21. Flipped Learning. Wilmington Montessori School. https://www. wmsde.org/programs/middleschool/flipped. Accessed May 21, 2021.

22. Hirumi A, Bradford G, Rutherford L. Selecting delivery systems and media to facilitate blended learning: a systematic process based on skill level, content stability, cost and instructional strategy. Journal for Online Learning and Teaching. 2011;7(4):489-501.

23. Hirumi A. Three levels of planned e-learning interactions: a framework for grounding research and the design of e-learning programs. Quarterly Review of Distance Education. 2013;14(1):1-16.

24. Hirumi A. The design and sequencing of e-learning interactions: a grounded approach. International Journal on E-Learning. 2002;1(1):19-27.

25. Keller JM. Motivational design for learning and performance: the ARCS model approach. US: Springer; 2010.

26. Li K, Keller JM. Use of the ARCS model in education: a literature review. Comput Educ. 2018;122:54-62. https://doi.org/10.1016/j. compedu.2018.03.019.

27. Hirumi A, Johnson K, Kleinsmith A, Reyes R, Rivera-Gutierrez D, Kubovec S, Bogert K, Lok B, Cendan J. Advancing virtual patient simulations and experiential learning with InterPLAY: examining how theory informs design and design informs theory. J Appl Instr Des. 2017;6(1):49-65. https://doi.org/10.28990/jaid2017.061005

28. Hirumi A, Johnson T, Reyes R, Johnson K, Rivera-Gutierrez D, Kleinsmith A, Kubovec S, Eakins M, Bogert K, Lok B, Cendan J. Advancing virtual patient simulations through design research and InterPLAY: Part II - testing and integration. Education Tech Research Dev. 2016;64(6):1301-35. https://doi.org/10.1007/ s11423-016-9461-6.

29. Hirumi A, Kleinsmith A, Johnson K, Kubovec S, Eakins M, Bogert K, Rivera-Gutierrez D, Reyes R, Lok B, Cendan J. Advancing virtual patient simulations through design research and InterPLAY: part I - design and development. Education Tech Research Dev. 2016;64(4):763-85. https://doi.org/10.1007/s11423-016-9429-6.

30. Hirumi A, Lok B, Johnson T, Johnson K, Rivera-Gutierrez D, Ramsamooj R, ...Cendan J. Nerve, interplay, and design-based research: advancing experiential learning and the design of virtual patient simulations. In JM Spector, BB Lockee, and MD Childress (Eds). Learning, Design, and Technology: An Interactional Compendium of Theory, Research, Practice, and Policy. New York, NY: Springer; 2018. pp. 1-50.

31. Gilbert TF. Human competence: engineering worthy performance. John Wiley \& Sons; 1978.

32. Rogers EM. Diffusion of Innovations, 5th Edition. Free Press; 2003.

33. Kapoor K, Dwivedi Y, Williams M. Rogers' innovation adoption attributes: a systematic review and synthesis of existing 
research. Inf Syst Manag. 2014;31(1):74-91. https://doi.org/10. 1080/10580530.2014.854103.

34. Hirumi A. Chronicling the challenges of Web-basing a degree program: a systems perspective. Q Rev Dist Learn. 2000;1(2):89-108.

35. Hirumi A, Ratliff M, De La Mora E. Analyzing your context to improve and innovate DL. In L Cifuentes (ed.). Guide to
Administering Distance Learning. Boston, MA: Brill Publishing; In press.

Publisher's Note Springer Nature remains neutral with regard to jurisdictional claims in published maps and institutional affiliations. 